\title{
Investigation on Al Doped ZnO thin Films and its n-AIZnO/p-Si Junction Diodes via dip Coating and JNSP Techniques
}

\author{
S. KALIDASS ${ }^{1,2}$, P. THIRUNAVUKKARASU ${ }^{1 *}$, M. BALAJI ${ }^{3}$ and J. CHANDRASEKARAN ${ }^{4}$ \\ 'Department of Electronics, Sri Ramakrishna Mission Vidyalaya College of Arts and Science, \\ Coimbatore 641020, Tamil Nadu, India. \\ 2Department of Electronics,Government Arts College, Trichirapalli 620022, Tamil Nadu, India. \\ ${ }^{3}$ Department of Physics, Bannari Amman Institute of Technology, Sathyamanglam, \\ Tamil Nadu 638401, India. \\ ${ }^{4}$ Department of Physics, Sri Ramakrishna Mission Vidyalaya College of Arts and Science, \\ Coimbatore 641020, Tamil Nadu, India. \\ ${ }^{*}$ Corresponding author E-mail: iruarasu@yahoo.co.in \\ http://dx.doi.org/10.13005/ojc/340548
}

(Received: June 20, 2018; Accepted: August 29, 2018)

\begin{abstract}
From this investigation, we find out that the dip coating and jet nebulizer spray pyrolysis (JNSP) techniques are the suitable to fabricate aluminum doped zinc oxide (AIZnO) thin films and the P-N junction diode of $\mathrm{n}-\mathrm{AIZnO} / \mathrm{p}-\mathrm{Si}$ at $450^{\circ} \mathrm{C}$. Several characterization techniques are used to measure the consequences of Al doping $(0,0.5,1.0,1.5,2.0$ and $2.5 \mathrm{wt} . \%)$ on structural, optical, electrical and diode properties of $\mathrm{ZnO}$. We recorded that the films were polycrystalline with a hexagonal structure of $\mathrm{ZnO}$ by the X-ray diffraction (XRD) analysis. The disparities of the sub-micro sized rod-like structures are observed from the scanning electron microscope (SEM) images. The energy dispersive X-ray spectroscopy (EDX) analysis proved that the elements of $\mathrm{Al}, \mathrm{Zn}$ and $\mathrm{O}$ were presented in the film. The absorbance and band gap energy $(\mathrm{Eg})$ values were ascertained from the ultraviolet visible (UV-Vis) analysis. By the current-voltage (I-V) characterization, the maximum conductivity value is detected for $1.5 \mathrm{wt}$.\% of $\mathrm{Al}$ doped $\mathrm{ZnO}$ film. The I-V measurement for finding the diode parameters of ideality factor $(\mathrm{n})$ and barrier height $(\Phi \mathrm{b})$ in dark and under light was taken.
\end{abstract}

Keywords: AIZnO thin films, Dip coating, P-N junction diode, JNSP technique.

\section{INTRODUCTION}

Nowadays, forming a p-n junction diode by transition metal oxide (TMO) as an n-type layer and silicon wafer as a p-type is convincing method for electronics industry. The recent survey concludes that the some TMOs of $\mathrm{MoO}_{3}, \mathrm{WO}_{3}, \mathrm{ZnO}$ and
$\mathrm{NiO}^{1}$ are widely used. Among these TMOs, $\mathrm{ZnO}$ has a wide band gap energy and it has required structural and electronic properties. Moreover, $\mathrm{ZnO}$ has been played a vital role in various applications of UV lasers and short-wavelength optoelectronic device ${ }^{2,3}$. Besides $\mathrm{ZnO}$ can be apt in the applications of photoconductors ${ }^{4}$, gas sensors ${ }^{5}$ and photovoltaic ${ }^{6}$. 
ZnO films can be grown using the following techniques such as thermal evaporation, spray pyrolysis, chemical vapour deposition, dip coating, etc., and ${ }^{7-14}$. Among them dip coating method was chosen from the list for preparing thin films and JNSP technique ${ }^{15,16}$ was opted for preparing $\mathrm{P}-\mathrm{N}$ junction diodes.

From this work, AlZnO thin films and $\mathrm{n}-\mathrm{AlMoO}_{3} / \mathrm{p}-\mathrm{Si}$ junction diodes with different doping concentrations of $\mathrm{Al}(0,0.5,1.0,1.5,2.0,2$ and 2.5 wt. $\%$ ) were developed at a annealed temperature of $450^{\circ} \mathrm{C}$ by dip coating practice and the diodes were groomed using JNSP technique. The structural, electrical and optical properties were obtained for dip coated $\mathrm{ZnO}$ films. From I-V measurement, the diode parameters of $\mathrm{n}$ and $\Phi \mathrm{b}$ were calculated for $\mathrm{n}-\mathrm{AlMoO}_{3} / \mathrm{p}-\mathrm{Si}$ junction diodes in dark and under light.

\section{EXPERIMENTAL}

Fabrication of $\mathrm{AlZnO}$ films and $\mathrm{n}-\mathrm{AlMoO}_{3} / \mathrm{p}-\mathrm{Si}$ diode

The starting solution was prepared with $0.10 \mathrm{M}$ of zinc acetate and aluminium acetate $(0,0.5,1.0,1.5,2.0$ and $2.5 \mathrm{wt} . \%)$ in $100 \mathrm{ml}$ of ethanol and stirred for $45 \mathrm{~min}$. Mono ethylamine (MEA) was added into the starting solution for ionizing and stirred for an hour. The well cleaned slide was dipped into the prepared solution and deionized water simultaneously for $30 \mathrm{sec}$. of 5 times. The deionized water was kept at $85^{\circ} \mathrm{C}$. After that, the prepared slides were annealed at $450^{\circ} \mathrm{C}$. Initially, the Si wafer cleaning is indispensable to construct a quality PN junction diode because there may be some impurities of dust, grease and organic residues present on the surface. A detailed study of steps involving in cleaning process has been known in a publication ${ }^{16}$. Using JNSP technique at $450^{\circ} \mathrm{C}$, the p-type Si wafer $(1 \times 1 \mathrm{~cm}$ size $)$ was coated with 1.5 $\mathrm{ml}$ of starting solution by spray method. The Silver (Ag) paste was applied and dried for $5 \mathrm{~h}$ at ambient condition to both surfaces of the prepared $\mathrm{n}-\mathrm{AlZnO}$ /p-Si diode for getting a better electrical contact owing to its notable properties of adhesion, electrical conductivity, low sheet resistance $(>0.02 \Omega / \mathrm{cm})$ and good solderability. The JNSP technique was used to fabricate diodes and the details are illustrated in some publications ${ }^{15,16}$.

\section{Characterization techniques}

The XPERT-PRO X-ray diffractometer (XRD) is fixed in the angle of diffraction $(2 \theta)$ range of
20 to $70^{\circ}$ with CuK $\alpha 1$ radiation of wavelength 1.5406 $\AA$ to measure the $2 \theta$ peaks which will be used to obtain the structural properties of the prepared thin films. JEOL JEM 2100 scanning electron microscope (SEM) was used to image the surface morphology of the prepared films. The QUANTA FEG 250 energy dispersive $\mathrm{X}$-ray spectroscopy (EDX) is helps to prove the presence of elements of $\mathrm{Al}, \mathrm{Zn}$ and $\mathrm{O}$ in the prepared films. Using Perkin Elmer Lambda 35 UV-Visible spectrophotometer (UV-Vis), the optical properties were explored in the visible region. Keithley Electrometer 6517-B was used to perceive the electrical properties and diode parameters of the AlZnO films and n-AIMoO$/ \mathrm{p}$-Si diode.

\section{RESULTS AND DISCUSSION}

\section{XRD pattern}

The XRD pattern for various wt.\% of $\mathrm{Al}$ doped $\mathrm{ZnO}$ films prepared at a sample temperature of $450^{\circ} \mathrm{C}$ noticeable all around air is appeared in Fig. 1. The Fig. 1 indicates the prepared Al doped ZnO films are polycrystalline with hexagonal structure of ZnO (JCPDS-Card No. 89-0510) for a favored orientation along ( $\left.\begin{array}{lll}1 & 0 & 1\end{array}\right)$ and other XRD crests at (0 02 2) and (1 00 ) planes. Likewise, Fig. 1, deciphers that no different phases typically identified from dip coated AIZnO films at $450^{\circ} \mathrm{C}$ because of (i) the base measure of Al element may display as little bunches in $\mathrm{ZnO}$ lattices, thus, it may be extremely hard to distinguish by XRD and (ii) most likely put in the grain boundaries of the $\mathrm{ZnO}$ nanocrystals - or dispersed atomically in the $\mathrm{ZnO}$ lattice $\mathrm{e}^{17-19}$.

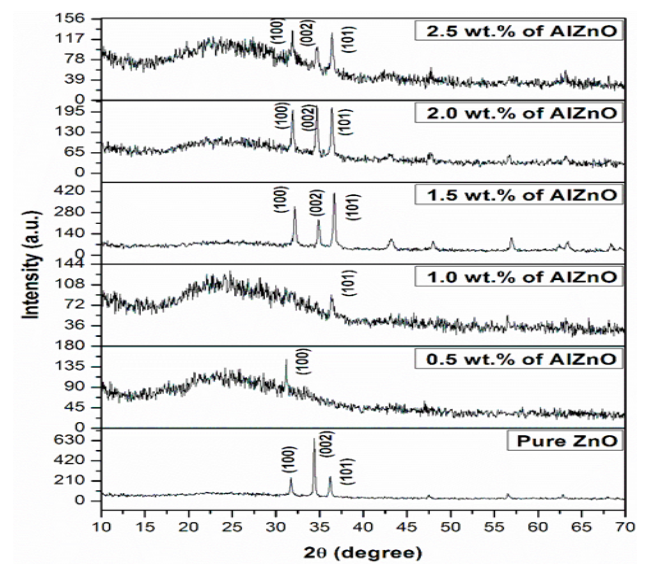

Fig. 1. XRD pattern of Al doped $\mathrm{ZnO}$ thin films for different concentrations of Al 
From Table 1, the structural parameters of AlZnO films for the chosen direction of $(040)$ plane. The parameters of crystallite size (D) ${ }^{20}$, microstrain $(\varepsilon)$, dislocation density $(\delta)$ and stacking fault $(\mathrm{SF})$ can be found the following relations $(1-4)^{16}$

$$
\begin{aligned}
\mathrm{D} & =\frac{\mathrm{k} \lambda}{\beta \cos \theta} \\
\varepsilon & =\frac{\beta \cos \theta}{4} \\
\delta & =\frac{1}{\mathrm{D}^{2}} \text { lines } / \mathrm{m}^{2}
\end{aligned}
$$

$$
\mathrm{SF}=\left[\frac{2 \pi^{2}}{45(3 \tan \theta)^{1 / 2}}\right] \beta
$$

Where $\mathrm{k}, \lambda, \theta$ and $\beta$ are the shape factor, wavelength of the $\mathrm{X}$-ray radiation, diffraction angle and full width at half maximum.

The $D$ values from 56.51 to $41.43 \mathrm{~nm}$ of the chosen direction ( 040 ) plane is obtained by Al concentration increment from 0 to 2.5 wt. $\%$. Microstrain, dislocation density and stacking fault values have changed with increasing of concentration (Table 1) $)^{21,22}$.

Table 1: Structural parameters of Al doped ZnO films for different doping concentrations of aluminium

\begin{tabular}{ccccc}
\hline $\begin{array}{l}\text { Al doping } \\
(\text { wt.\%) }\end{array}$ & $\begin{array}{c}\text { Crystallite } \\
\text { size }(\mathrm{D}) \\
(\mathrm{nm})\end{array}$ & $\begin{array}{c}\text { Micro } \\
\text { strain }(\varepsilon) \\
\left(\times 10^{-3} \text { lines }^{-2} \mathrm{~m}^{-4}\right)\end{array}$ & $\begin{array}{c}\text { Dislocation } \\
\text { density } \\
\left(\times 1014 \mathrm{~cm}^{-2}\right)\end{array}$ & $\begin{array}{c}\text { Stacking Fault } \\
\left(\times 10^{-2}\right)\end{array}$ \\
\hline 0 & 56.411 & 0.6149 & 3.1424 & 0.1619 \\
0.5 & 56.42 & 0.6113 & 3.1072 & 0.1597 \\
1 & 56.51 & 0.6095 & 3.0964 & 0.1579 \\
1.5 & 56.605 & 0.5908 & 2.9986 & 0.1454 \\
2 & 53.31 & 0.6507 & 3.5185 & 0.1403 \\
2.5 & 41.43 & 0.8371 & 5.8211 & 0.1816 \\
\hline
\end{tabular}

\section{SEM Analysis}

Figure 2a-f illustrates the morphological images of the prepared AIZnO thin films for different concentrations $(0,0.5,1.0,1.5,2.0$ and 2.5 wt.\%) of Al. The hexagonal faced rod-like structures with random in alignment are found to pure $\mathrm{ZnO}$ (Fig. $2 a \&$ b). The concentration of Al from 1.0 to $2.0 \mathrm{wt}$.\%

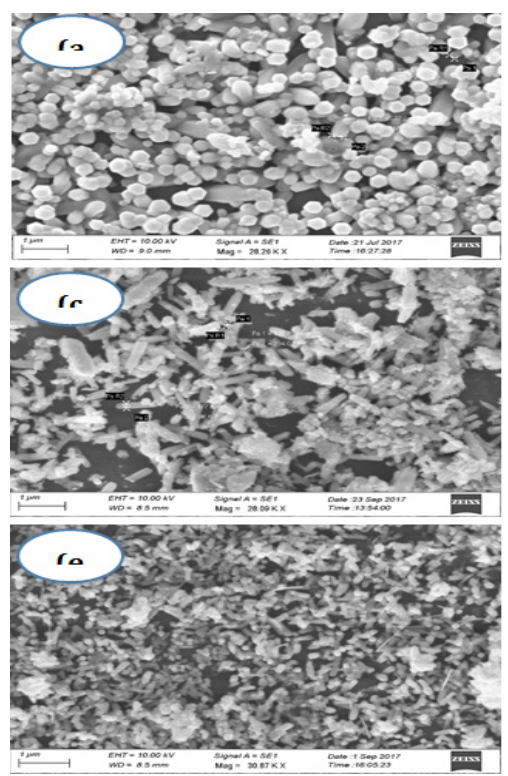

portrays the randomly arranged micro-rod like structures (Fig. 2c-e). 2.5 wt.\% of Al doped ZnO film exhibits the agglomeration in grains, which shows hasty disparity nature of rods compare to low concentrations of Al doped ZnOfilms (Fig. 2f). It results that the surface morphology of the dip coated AlZnO films remarkably varied by $\mathrm{Al}$ concentrations.

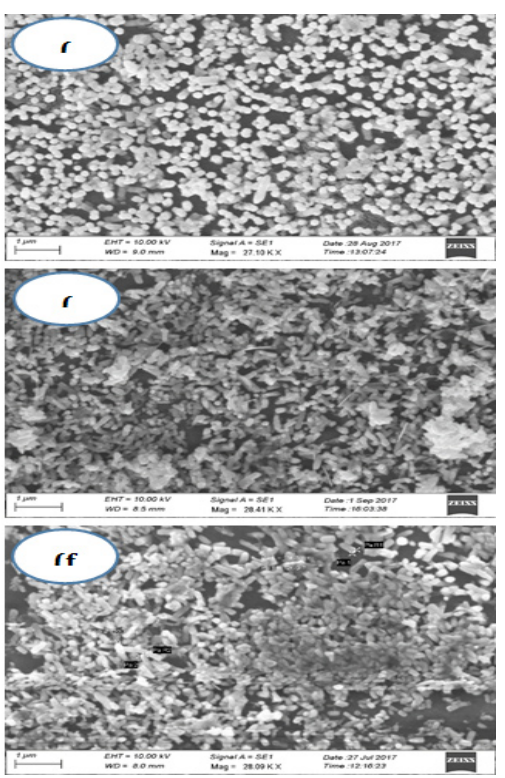

Fig. 2. SEM images of Al doped ZnO thin films for different concentrations of a) 0, b) 0.5, c) 1.0, d) 1.5, e) 2.0 and f) 2.5 wt.\% of Al 


\section{EDX spectra}

The EDX spectra of the dip coated AIZnO thin films for various concentrations $(0,0.5$ and 2.5 wt.\%) of $\mathrm{Al}$ is shown in Fig. 3. The elements of $\mathrm{Al}$,

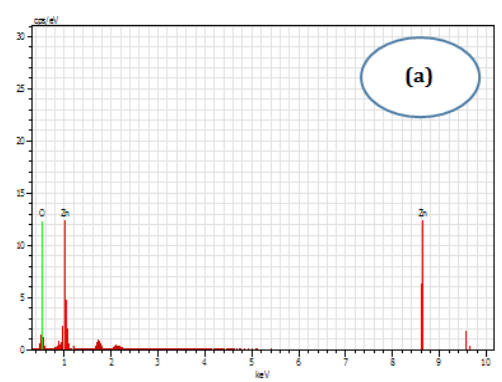

$\mathrm{Zn}$ and $\mathrm{O}$ with no additional elements present in the dip coated AIZnO films were confirmed by the EDX spectra. The increasing of Al concentrations results that the atomic ratio of $\mathrm{Al}$ in increased.

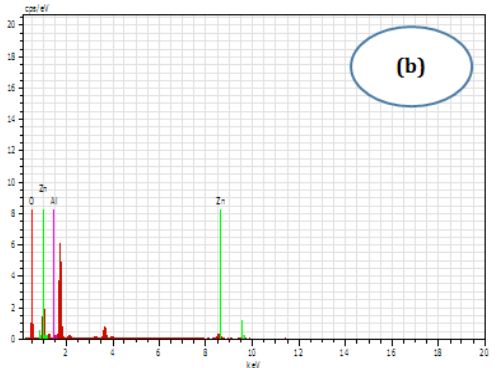

(c)

Fig. 3. EDX pattern of Al doped ZnO thin films for different concentrations of a) 0, b) 0.5, and c) $2.5 \mathrm{wt} . \%$ of Al.

Table 2: Atomic ratio for $\mathrm{Al}$ doped ZnO thin films

\begin{tabular}{cccc}
\hline $\begin{array}{c}\text { Al doping } \\
\text { concentration } \\
\text { (wt.\%) }\end{array}$ & \multicolumn{3}{c}{ Atomic ratio (\%) } \\
\hline 0 & $\mathrm{Al}$ & $\mathrm{Zn}$ & $\mathrm{O}$ \\
0.5 & 0 & 55.10 & 44.90 \\
2.5 & 1.04 & 51.20 & 47.76 \\
\hline
\end{tabular}

\section{UV-Vis spectroscopy}

From Fig. 4, the absorbance spectra depicts the dip coated pure $\mathrm{ZnO}$ and $\mathrm{Al}$ doped $\mathrm{ZnO}$ films prepared at $450^{\circ} \mathrm{C}$ of sample temperature. From the Fig. 4, the absorbance values slightly varied by increasing the concentration of Al. Among the different concentrations of $\mathrm{Al}$ with $\mathrm{ZnO}$ films except pure $\mathrm{ZnO}$, $1.5 \mathrm{wt} \%$ of $\mathrm{Al}$ doped $\mathrm{ZnO}$ is recorded with minimum absorbance value. The concentration of Al varies the density of unsaturated bonds which results the changes in absorbance. In general, transmission from valance to conduction band states the optical absorbance but absorption in visible range suggests the unchanged localized energy states in band gap ${ }^{23}$.

Eg values of the AIZnO films have been calculated by UV-Vis spectra with the following eqn. (5) ${ }^{16,24}$,

$\alpha h v^{n}=B\left(h v-E_{g}\right)$

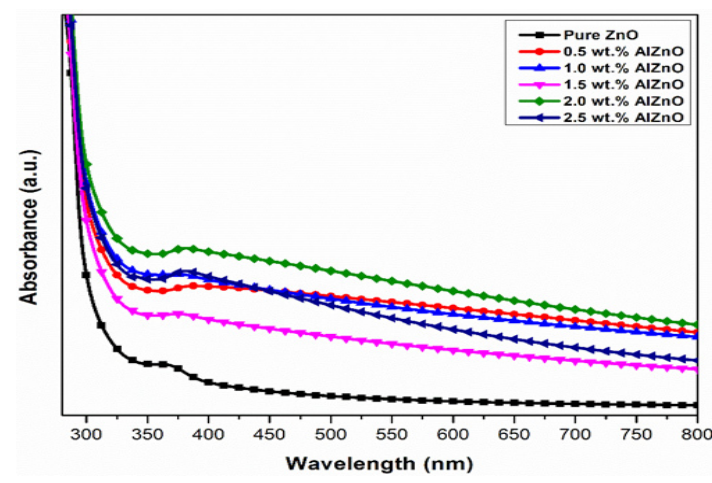

Fig. 4. UV-Vis spectrum of $\mathrm{Al}$ doped $\mathrm{ZnO}$ thin films for different concentrations of $\mathrm{AI}$

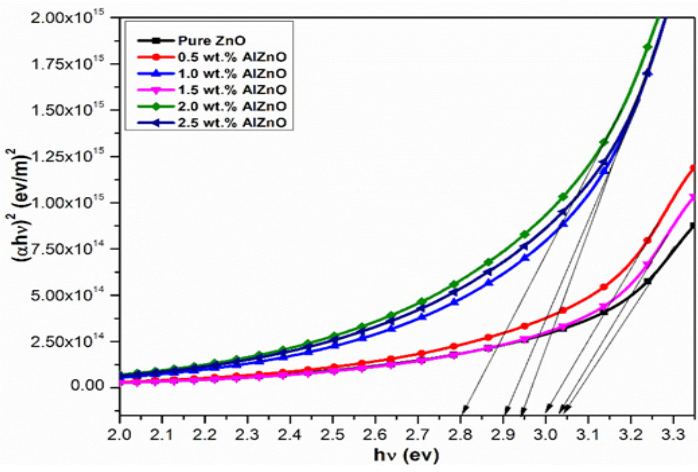

Fig. 5. Band energy values of Al doped $\mathrm{ZnO}$ thin films for different concentrations of $\mathrm{Al}$ 
Plot of $(\alpha h v)^{2}$ Vs. (hu) for different concentrations of $\mathrm{Al}$ doped $\mathrm{ZnO}$ films is drawn as shown in Fig. 5. The direct band gap nature of prepared AlZnO films is identified by straight line portion of the plot. $E_{g}$ values of $3.03 \mathrm{eV}$ for the undoped $\mathrm{ZnO}$ film and 3.00, 2.90, 3.20, 2.80 and $2.94 \mathrm{eV}$ for various concentrations $(0.5,1.0,1.5$, 2.0 and $2.5 \mathrm{wt}$. \%) of $\mathrm{Al}$ doped $\mathrm{ZnO}$ was attained by extrapolating a line to the axis of hu. $1.5 \mathrm{wt} . \%$ of $\mathrm{Al}$ doped $\mathrm{ZnO}$ reveals maximum $\mathrm{E}_{\mathrm{q}}$ values compare to other doping concentrations of Al doped $\mathrm{ZnO}$ films except pure one. The variation in $\mathrm{E}_{\mathrm{g}}$ may be due to the increasing of defects in structural parameters while preparing the $\mathrm{AIZnO}$ films ${ }^{24}$.

\section{Current (I) - Voltage (V) characterization I-V characterization of electrical conductivity $(\sigma)$}

The I-V measurement was noted at ambient condition for the prepared AIZnO films for different concentrations of Al by Keithley electrometer 6517-B. The applied voltage is $10-100 \mathrm{~V}$ (increasing of of $10 \mathrm{~V}$ ) on the prepared thin films and its corresponding current flow is measured. The I-V plot of AIZnO thin films for various concentrations $(0,0.5,1.0,1.5,2.0$ and $2.5 \mathrm{wt} . \%$ ) of $\mathrm{Al}$ is displayed in Fig. 6. The values of current are considerably changed for increasing Al concentration with its respective applied voltage (Figure 6).

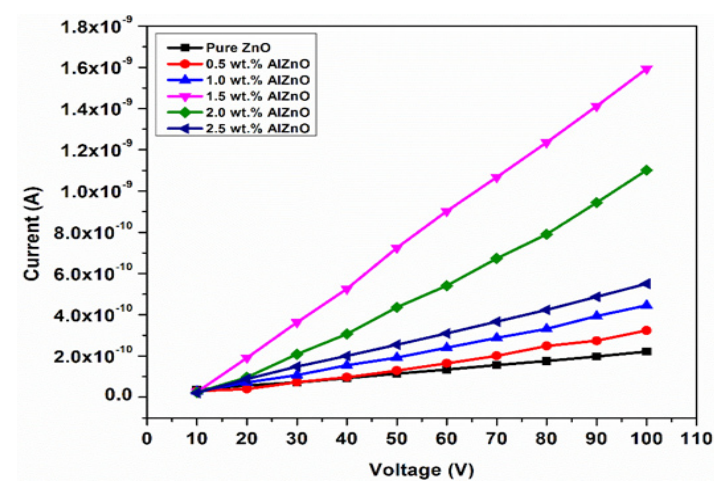

Fig. 6. I-V characteristics of Al doped $\mathrm{ZnO}$ thin films for different concentrations of $\mathrm{Al}$

The $\sigma$ value has been attained using the given eqn. $(6)^{16}$,

$$
\sigma=\left(\frac{\mathrm{I}}{\mathrm{V}}\right) \times\left(\frac{\mathrm{d}}{\mathrm{A}}\right)
$$

Where I, V, d, and A are the current, applied voltage, inter-probe distance and cross-sectional area of the film.

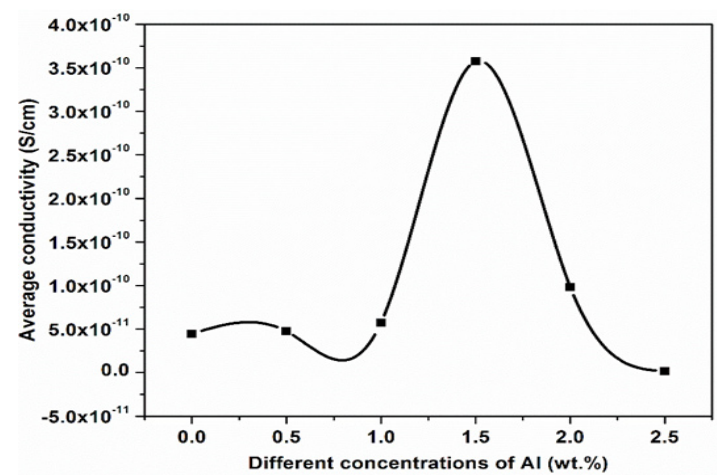

Fig. 7. Average conductivity values of $\mathrm{Al}$ doped $\mathrm{ZnO}$ thin films for different concentrations of Al

The Average conductivity $\left(\sigma_{\text {avg }}\right)$ values of AlZnO films varied by increasing the concentration of $\mathrm{Al}$ (Fig. 7). The $\sigma_{\text {avg }}$ values for pure $\mathrm{ZnO}$ and 0.5 , $1.0,1.5,2.0$ and 2.5 wt.\% of $\mathrm{Al}$ doped $\mathrm{ZnO}$ are $4.464 \times 10^{-11}, 4.751 \times 10^{-11}, 5.731 \times 10^{-11}, 3.575 \times$ $10^{-10}, 9.811 \times 10^{-11}$ and $1.588 \times 10^{-12} \mathrm{~S} / \mathrm{cm}$ (Fig. 7). From the results, $1.5 \mathrm{wt} . \% \mathrm{Al}$ doped $\mathrm{ZnO}$ reveals the maximum $\sigma_{\text {avg }}$ value. The obtained results might be due to the oxygen vacancies ${ }^{25-27}$ of AIZnO films.

\section{I-V characterization of $\mathrm{n}-\mathrm{AlZnO/p-Si} \mathrm{diode}$}

The prepared $\mathrm{n}-\mathrm{AlZnO} / \mathrm{p}-\mathrm{Si}$ junction diodes for pure and $1.5 \mathrm{wt} . \%$ of Al doped $\mathrm{ZnO}$ were studied as shown in Figure 8a\&b and the parameters of $\mathrm{n}$ and $\Phi_{\mathrm{b}}$ values in dark and under light were calculated. Fig. 9a \& $b$ indicates the semi-log plot of current density (In J) Vs. voltage (V). The voltage of reverse to forward bias from -4 to $+4 \mathrm{~V}$ was applied and its corresponding current value is measured which indicates a good rectification of $n-A I Z n O / p-S i$ junction diodes.

The $\mathrm{J}$ values for the prepared $\mathrm{n}-\mathrm{AlZnO} / \mathrm{p}-\mathrm{Si}$ junction diodes have been calculated using the thermionic emission theory (TE) as given below eqn. $(7)^{28}$,

$$
\mathrm{J}=\mathrm{J}_{\mathrm{o}} \exp \left(\frac{\mathrm{qV}}{\mathrm{nKT}}-\mathbf{1}\right)
$$

Where $\mathrm{J}_{0}, \mathrm{q}, \mathrm{V}, \mathrm{n}, \mathrm{K}$ and $\mathrm{T}$ is the reverse saturation current density, electron charge, applied voltage, ideality factor, $\mathrm{K}$ Boltzmann constant and absolute temperature.

The $\mathrm{n}$ value and $\Phi_{\mathrm{b}}$ have been calculated using the eqns. $(8,9)^{29}$

$$
\begin{aligned}
& \mathbf{n}=\frac{\mathbf{q}}{\mathrm{KT}} \frac{\mathrm{dV}}{\mathrm{d}(\ln \mathrm{J})} \\
& \boldsymbol{\Phi}_{\mathbf{b}}=\frac{\mathrm{KT}}{\mathbf{q}} \ln \left(\frac{A^{*} \mathbf{T}^{2}}{J_{o}}\right)
\end{aligned}
$$

Where $A^{*}$ is the Richardson constant. 

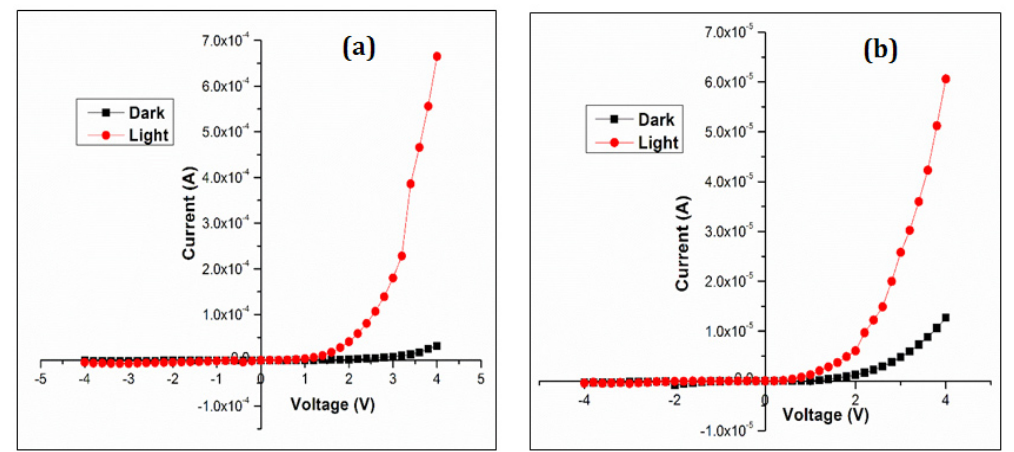

Fig. 8. I-V characteristics of $\mathrm{n}-\mathrm{AIZnO} / \mathrm{p}-\mathrm{Si}$ junction diodes for a) 0 and b) $1.5 \mathrm{wt} . \%$ of $\mathrm{Al}$ in darkness and under light
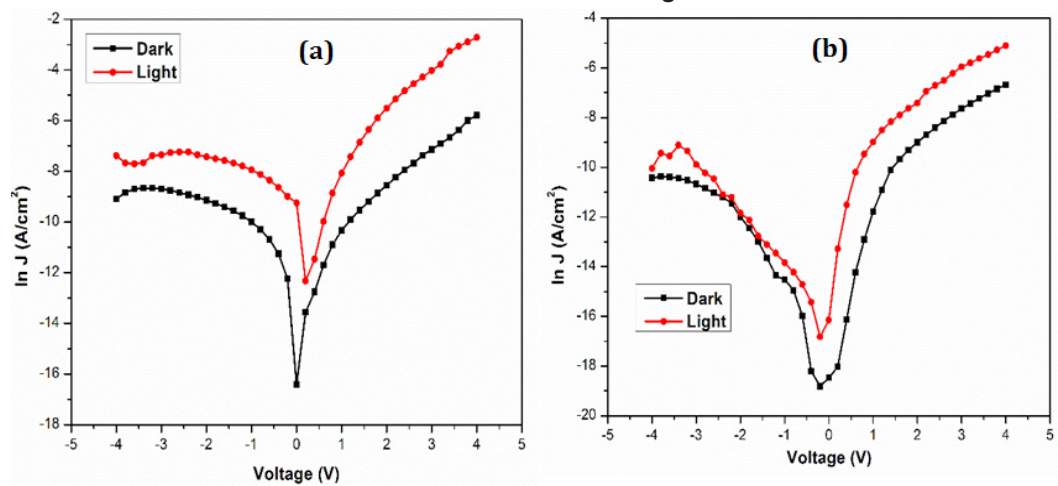

Fig. 9: Semi-log plots of n-AIZnO /p-Si junction diodes for a) 0 and b) 1.5 wt.\% of AI

in darkness and under light

From calculated values, the $\mathrm{n}$ values for pure and $1.5 \%$ Al doped $\mathrm{n}-\mathrm{ZnO} / \mathrm{p}$-Si diodes are 4.08 and 4.34 in darkness but under the light, it decreases into 3.32 and 3.69. The variation in $n$ values might be due to the absorption of prepared $\mathrm{AlZnO}$ thin films with its thickness and also might be due to the conversion efficiency of Si wafer ${ }^{30}$.

The $n$ values of the prepared $n-\mathrm{ZnO} / \mathrm{p}-\mathrm{Si}$ diodes are higher than the ideal value of one which indicates the non-ideal behavior of prepared diodes. The reasons may be owing to the occurrence of interfacial thin oxide $\left(\mathrm{SiO}_{2}\right)$ layer between electrode of $\mathrm{Ag}$ and $\mathrm{Si}$ wafer or the recombination of current or bias dependent $\Phi_{\mathrm{b}}{ }^{31}$. Additional causes might be owing to defects of the states on the surface of the semiconductor ${ }^{32,33}$, chemical reactions and barrier inhomogeneities ${ }^{34}$.

\section{CONCLUSION}

The preparation of $\mathrm{AIZnO}$ films for various concentrations (0, 0.5, 1.0, 1.5, 2.0 and $2.5 \mathrm{wt} . \%)$ of $\mathrm{Al}$ at the annealing temperature of $450^{\circ} \mathrm{C}$ using dip coating method. XRD pattern shows that the dip coated AIZnO films exhibited a hexagonal structure and $D$ is varied from 41.43 to $56.61 \mathrm{~nm}$ as increase in $\mathrm{Al}$ concentrations. From SEM result, the surface morphology is vastly disturbed by the concentration of Al. The confirmation of $\mathrm{Al}, \mathrm{Zn}$ and $O$ element existence in the present work is observed by EDX analysis. In UV-Vis analysis, the $1.5 \mathrm{wt} . \% \mathrm{Al}$ doped $\mathrm{ZnO}$ film gives a minimum absorbance value compared to other doping concentrations of $\mathrm{Al}$ and $E_{g}$ value was changed from 2.80 to $3.03 \mathrm{eV}$. I-V characteristic reveals that a maximum $\sigma$ of $3.575 \mathrm{x}$ $10^{-10} \mathrm{~S} / \mathrm{cm}$ was reached for $1.5 \mathrm{wt} . \%$ Al doped $\mathrm{ZnO}$ film. The JNSP technique is used to the prepare $\mathrm{n}-\mathrm{ZnO} / \mathrm{p}-\mathrm{Si}$ diodes for various concentrations $(0$ and $1.5 \mathrm{wt} . \%)$ of $\mathrm{Al}$ at the sample temperature of $450^{\circ} \mathrm{C}$. the minimum $n$ values of 3.32 and 3.69 for pure and $1.5 \mathrm{wt} . \% \mathrm{n}$-AIZnO/p-Si diode under light.

\section{ACKNOWLEDGEMENT}

The authors gratefully acknowledge Dr. N. Anandhan, Alagappa University, Karaikudi, Dr. V. Manickam, St. Joseph's College (Autonomous), Tiruchirapalli and ARIC, SRMV College of Arts and Science, Coimbatore, for providing instrumentation facilities. 


\section{REFERENCES}

1. Bao, D.; Gu, H.; Kuang, A. Thin Solid Films ., 1998, 312, 37-39.

2. Dong, H.; Zhou, B.; Li, J.; Zhan, J.; Zhang, L. J. Materiomics., 2017, 3, 255-266.

3. Ohshima, T.; Ikegami, T.; Ebihara, K.; Thareja, R.K. Electrical Engineering in Japan., 2002, 122-A, 689-694.

4. Haga, Y.; Inoue, S.; Sato, T.; Yosomiya, R. Angew. makromol. chem., 1986, 139, 49-61.

5. Balram, D.; Lian, K.Y.; Sebastian, N. Int. J. Electrochem. Sci., 2018, 13, 1542-1555.

6. Dumbrava, A.; Prodan, G.; Moscalu, F.; Mater. Sci. Semicond. Process., 2013, 16, 1095-1104.

7. Manzi, J.A.; Knapp, C.E.; Parkin, I.P.; Carmalt, C. J. Eur. J. Inorg. Chem., 2015, 3658-3665.

8. Shanmugasundaram, K.; Thirunavukkarasu, P.; Ramamurthy, M.; Balaji, M.; Chandrasekaran, J. Orient. J. Chem., 2017, 33, 1-7.

9. Dumbrava, A.; Prodan, G.; Moscalu F. Mater. Sci. Semicond. Process., 2013, 16, 1095-1104

10. Alfaro Cruz, M.R.; Ortega Zarzosa, G.; Martinez Castanon, G.; Martinez, J.R. Mater. Lett., 2012, 78, 159-161.

11. Bhattacharyya, P.; Basu, P.K.; Saha, H.; Basu, S. Sens. Actuators B., 2007, 124, 62-67.

12. Lupan, O.; Pauporte, T.; Chow, L.; Viana, B.; Pelle, F.; Ono, L.K.; Roldan Cuenya, B.; Heinrich, $\mathrm{H}$. Appl. Surf. Sci., 2010, 256, 1895-1907.

13. Zhao, L.; Lian, J.; Liu, Y.; Jiang, Q. Appl. Surf. Sci., 2006, 252, 8451-8455.

14. Thambidurai, M.; Muthukumarasamy, N.; Velauthapillai, D.; Lee, C. J. Mater. Sci: Mater. Electron., 2012, DOI 10.1007/s10854-012-1035-8.

15. Sethupathi, N.;Thirunavukkarasu, P.;Vidhya, V.S.; Thangamuthu, R.; Kiruthika, G.V.M.; Perumal, K.; Bajaj, H.C.; Jayachandran, M.J. Mater. Sci. Mater. Electron., 2012, 23, 1087-1093.

16. Balaji, M.; Chandrasekaran, J.; Raja, M. Mater. Sci. Semicond. Process. 2016, 43, 104-113. Song, X.C.; Yang, E.; Liu, G.; Zhang, Y.; Liu, Z.S.; Chen, H.F.; Wang, Y. J. Nanopart. Res., 2010, 12, 2813.
17. Reddy, A.S.; Figueiredo, N.M.; Cho, H.C.; Lee, K.S.; Cavaleiro, A. Mater. Chem. Phys., 2012, 133, 1024.

18. O-Rueda de Leon, J.M.; Acosta, D.R.; Pal, U.; Castaneda, L. Electrochim. Acta., 2011, 56, 2599.

19. Scherrer, P. Nachr. Ges. Wiss. Gottingen. 1918, 26, 98.

20. Madhavi, V.; Kumar, P.J.; Kondaiah, P.; Hussain, O.M.; Uthanna, S. Ionics., 2014, DOI:10.1007/s11581-014-1073-8.

21. Lethy, K.J.; Beena, D.; Pillai, V.P.M.; Ganesan, V. J. Appl. Phys., 2008, 104, 033515.

22. Mishra, R.K.; Sahay, P.P. Mater. Res. Bull., 2012, 47, 4112.

23. Luo, Y.; Yin, B.; Zhang, H.; Qiu, Y.; Lei, J.; Chang, Y.; Zhao, Y.; Ji, J.; Hu, L. J. Mater. Sci.: Mater. Electron., 2016, 27, 2342.

24. Nirupama, V.; Chandrasekhar, M.; Radhika, P.; Sreedhar, B.; Uthanna, S. J. Optoelectron. Adv. Mater., 2009, 11, 320.

25. Nirupama, V.; Chandrasekhar, M.; Subramanyam, T.K.; Uthanna, S.; J. Phy. Conf. Ser., 2010, 208, 012101.

26. Sutrave, D.S.; Gothe, S.D. Int. Sci. J., 2015, 2, 2348.

27. Sze, S.M. Semiconductor Devices, 2nd ed. (Wiley, New York)., 2001, 224.

28. Ugurel, S.A.E.; Serifoglu, K.; Turut, A. Microelectron. Eng., 2008, 85, 2299.

29. Canfield, L.R.; Vest, R.; Woods, T.N.; Korde, R. Ultraviolet Tech. V., 1994, 2282, 31.

30. Padma, R.; Nagaraju, G.; Rajagopal Reddy, V.; Choi, C. J. Thin Solid Films., 2015, DOI:10.1016/j.tsf. 2015, 12, 018.

31. Dogan, H.; Yildrim, N.; Turut, A. Microelectron. Eng., 2008, 85, 655.

32. Sze, S.M. Physics of Semiconductor Devices, 2nd edn. (Wiley, New York, 1981)

33. Rhoderick, E.H.; Williams, R.H. Metalsemiconductor Contacts (Clarendon Press, Oxford, 1988) 